\title{
Prediction of Difficult Airway by Correlating Physical Indices with Maxillo-Pharyngeal Angle, Measured on Lateral Cervical Radiograph- an Analytical Study
}

\author{
Usman Anwar', Kumkum Gupta ${ }^{2}$, Prashant K Gupta ${ }^{3}$, Ivesh Singh ${ }^{4}$, Abhishake Kumar ${ }^{4}$, Pavitra Kalra ${ }^{1}$ \\ ${ }^{1}$ Resident, ${ }^{2}$ Professor, ${ }^{4}$ Assistant Professor, Department of Anaesthesiology and Critical Care, ${ }^{3}$ Director Professor, Department of Radio diagnosis and \\ Imaging, Subharti Medical College, Swami Vivekanand Subharti University, NH-58, By Pass Road, Meerut-UP, India.
}

\section{Abstract}

Background: The ability to predict difficult laryngoscopy preoperatively allows anaesthesiologists to take precautions to reduce the anesthesia-related risks but till now, no single airway test can provide a high index of sensitivity and specificity for prediction of difficult airway. The present analytical study was aimed to correlate the various physical indices with maxillo-pharyngeal angle, measured on lateral cervical radiograph, for preoperative prediction of difficult airway. Subjects and Methods: After approval from Institutional Ethical Committee and written informed consent, 200 patients of ASA physical status I and II, aged between 18 to 58 years of either gender with BMI $<25 \mathrm{Kg} / \mathrm{m}^{2}$, were studied. Patients with any obvious airway related abnormality, restricted mouth opening, short and thick neck, fixation of the trachea, malformation of the skull, teeth or mandible were excluded. Preoperatively, they were assessed for Modified Mallampati grading, thyromental distance, protrusion of jaw and head-neck movements along with Maxillo-pharyngeal angle, measured on lateral cervical radiograph. These parameters were correlated with Cormack Lehane grading during direct laryngoscopy. The observed data were analyzed by using one way analysis of variance (ANOVA) and Pearson's correlating co-efficient. Results: Modified Mallampati test sensitivity and specificity was found as $39.29 \%$ and $65.12 \%$ respectively with accuracy of $61.5 \%$. The sensitivity and specificity of Maxillo- Pharyngeal Angle was $85.71 \%$ and $97.09 \%$ respectively with accuracy of $95.50 \%$. Conclusion: The combination of various physical indices along with maxillo-pharyngeal angle in parallel is more sensitive and specific with clinically relevant higher discriminative power.

Keywords: Airway Assessment, Cormack and Lehane grading, Difficult airway, Modified Mallampati grading, Maxillo-pharyngeal angle.

Corresponding Author: Prof (Dr) Kumkum Gupta, 108-109, Chanakyapuri, Shastri Nagar, Meerut-250004 U.P. India.

Received: October 2018

Accepted: November 2018

\section{Introduction}

Most common concern of anaesthesiologists is the airway management as its difficulty is a major cause of anesthesiarelated morbidity in clinical practice. In fact, up to $28 \%$ of all anesthesia related deaths are secondary to the inability to either mask ventilate or intubate the patient, as few patients remain undetected despite the most careful preoperative airway evaluation. ${ }^{[1]}$ Accurate prediction of difficult airway may reduce potential complications by allowing the allocation of experienced personnel and use of relevant equipment.

Unanticipated difficult airway can occur due to the combination of several minor physical anomalies when no single factor is severely abnormal. Certain conditions such as obesity, pregnancy, a short neck, buck teeth, receding mandible and the presence of beard obviously go in favour of difficult airway. The existing predictors of difficult airway are not sensitive or specific enough for routine clinical use. $^{[2,3]}$

The Mallampati grading, thyromental distance, movements of jaw and head extension with neck flexion reliably predicts difficult intubation which could be compared with the degree of laryngeal exposure according to Cormack and Lehane grading. ${ }^{[4,5]}$ The maxillo-pharyngeal angle, an upper airway anatomical balance, was proposed for better understanding the patho-physiology of difficult laryngoscopy. ${ }^{[6-8]}$

The present prospective observation analytical study was aimed to correlate a simple, reproducible, and non-invasive radiological method with various physical indices for preoperative prediction of the difficult airway.

\section{Subjects and Methods}

After approval from Institutional Ethical Committee and written informed consent, 200 adult patients of ASA physical status I and II, aged between 18 to 58 years of either gender with BMI $<25 \mathrm{Kg} / \mathrm{m} 2$, were evaluated during the period from July 2016 to June 2018. The study was designed as prospective non-randomized observational analytical study. All patients underwent the pre-anesthetic assessment which included a detailed history. Their physical examination included general condition, built, weight, height and their 
systemic examination was performed to rule out any systemic illness.

The upper airway examination was done to rule out any obvious anomaly (congenital or traumatic) or pathology which could affect the direct laryngoscopy and intubation. The other specified examination included Modified Mallampati grading, thyromental distance, jaw movements to observe the rotation of condyle in the synovial cavity and head extension and neck flexion movement at neck, before enrolment them for the present study.

Patients with any airway related problems, cervical collars or traction devices, external trauma, restricted mouth opening, long and narrow mouth with a high-arched palate, short, thick and muscular neck, neck masses and fixation of the trachea, malformation of the skull, teeth or mandible and patients with massive obesity and history of snoring, were excluded from the study.

Airway assessment techniques

All patients were assessed for their airway anatomy by using following parameters-

1. Weight and Height -The weight of the patients was noted in kilograms $(\mathrm{kg})$ on a weighing scale and the height was measured in centimeters $(\mathrm{cm})$.

2. Modified Mallampati Grading-This method of assessment give an indirect means of evaluating the relative proportionality of size of posterior part of tongue to capacity of oro-pharynx. It was performed with the patient in the sitting position. The mouth was opened as wide as possible with protrusion of the tongue to its maximum without phonation. The observer's eye was at the level of the patient's mouth with good illumination. Now the degree to which faucial pillars, uvula, soft palate and hard palate were visible, classification was assigned. To avoid false positive or false negative, this test was repeated twice.

Grade I: Visualization of the faucial pillars, uvula, soft and hard palate, Grade II: Visualization of the uvula, soft and hard palate, Grade III: Visualization of base of uvula or none, visible soft and hard palate, Grade IV: Only hard palate is visible.

3. Thyromental Distance-The space anterior to the larynx is expressed as thyromental distance. This is the distance between the thyroid notch and mental symphysis when the patient's neck was fully extended. This space determines how easily the laryngeal and pharyngeal axis will fall in line when the atlanto- occipital joint is extended and laryngoscopy pushes the tongue into this space. If the distance is more than $6.5 \mathrm{~cm}$, there will be no problem with airway but if it is $6-6.5 \mathrm{~cm}$ without other concomitant anatomical problem, laryngoscopy and intubation may be difficult but not impossible, but if the distance is less than 6 $\mathrm{cm}$, it will be a difficult airway.

4. Protrusion of Jaw- It tested the range and freedom of mandibular movement and the architecture of the teeth. The patient was asked to protrude the mandible as far as possible and position of lower incisor in relation to lower incisor was assessed and interpreted as follows: Class I-Lower incisors could bite the upper lip above the vermillion line, Class IILower incisors could bite the upper lip below the vermillion line, Class III: Lower incisors could not bite the upper lip.
The latter two suggests reduced view at laryngoscopy.

5. Neck movements-The neck flexion was assessed by asking the patient to touch his manubrium sternum with his chin to assure adequate neck flexion of $25^{\circ}$ to $30^{\circ}$ at lower cervical spine. Now, the patient was asked to look at the ceiling without raising the eyebrows to assess the atlanto-occipital (A-O) joint function. Reduce A-O extension is a clear pointer to difficult airway.

6. Cormack and Lehane Grading- It assessed the degree of glottis visualization during direct laryngoscopy. Cormack and Lehane graded the difficulty in intubation according to the view obtained during direct laryngoscopy. The four grades of laryngoscopic views are as follows: Grade I Visualization of entire laryngeal aperture and no extrinsic manipulation of the larynx is required, Grade II Visualization of only posterior commissure of laryngeal aperture and external manipulation (BURP manoeuvre) of the larynx is necessary for intubation, Grade III Visualization of only epiglottis and intubation possible only when aided by a stylet, and Grade IV-Visualization of just the soft palate with failed intubation.

7. Maxillo-pharyngeal angle- It is closely related with the extension of the neck at the atlanto-occipital joint. The maxillo-pharyngeal angle (MP-A) is formed by the maxillary axis and the pharyngeal axis and measured on a lateral cervical radiograph. The Maxillary axis (MA) is the line parallel to the hard palate and the Pharyngeal Axis (PA) is the line passing through the anterior portion of the first (atlas) and second cervical vertebra. Normally the maxillopharyngeal angle should be greater than $100^{\circ}$ for ease of intubation. [Figure 1, 2]

Radiological measurement of Maxillo Pharyngeal Angle: A lateral cervical radiograph is taken in erect posture of patients with the neutral position of head with jaw in the natural occlusive position. The MP angle is measured electronically, by an experienced radiologist.

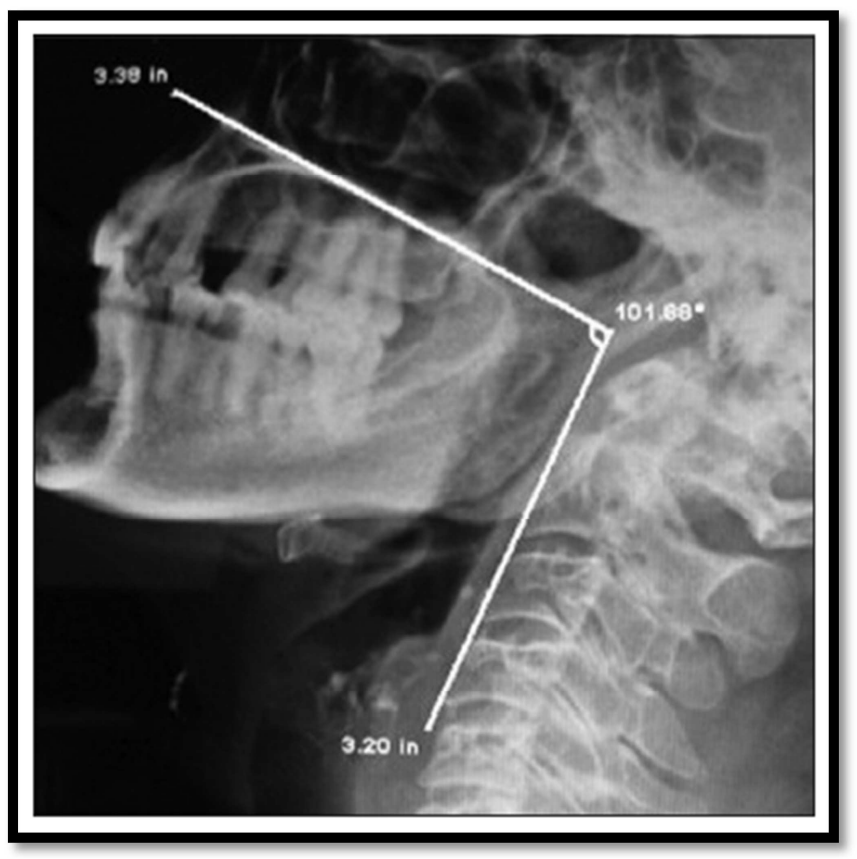

Figure 1: Showing the Maxillo- pharyngeal angle (MP angle) 


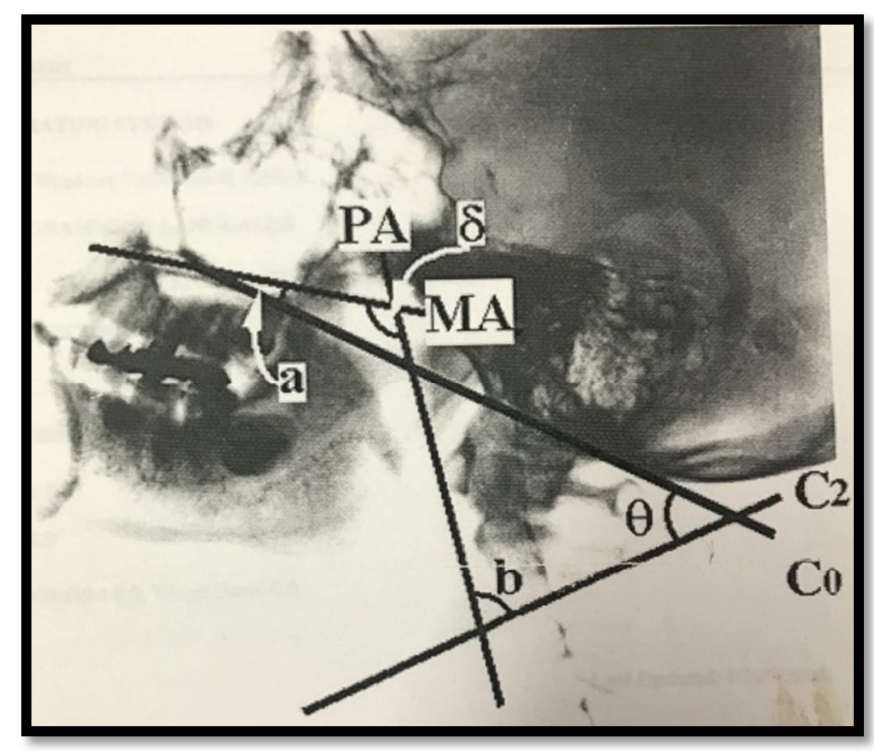

Figure 2: Showing Maxillary axis (MA) and Pharyngeal axis (PA)

These various physical airway assessment parameters and maxilla-pharyngeal angle, were correlated together with their Cormack and Lehane grading during direct laryngoscopy, to express the predictors of difficult airway.

\section{$\underline{\text { Sample size }}$}

Preliminary sample size was based on previous studies, which indicated that approximately 185 to 190 patients should be included in order to ensure power of $80 \%$ and alpha error of 0.05 with confidence limit of $95 \%$ for predicting clinically useful criteria for preoperative assessment of difficult airway. Assuming a dropout rate of $5 \%$, a total 200 adult patients were incorporated in the study for better validation of results.

\section{Statistical analysis}

The data obtained in the study was presented in a tabulated manner and variables were expressed as mean \pm standard deviation (SD). Stat graphic Centurion, version 16 (Stat point-Technologies INC, Warrenton, Virginia) was used and demographic parameters were analyzed using one way analysis of variance (ANOVA). Data of airway assessments was correlated using Pearson's correlating co-efficient and results were depicted as kappa value.

\section{Results}

The present prospective observational analytical study was conducted on 200 patients and their physical indices of airway assessment were correlated with maxillo-pharyngeal angle, to predict difficult airway.

\section{Demographic profile}

Patient's age, weight, height, gender ratio, BMI and ASA physical status were considered as demographic parameters. The mean age of patients was $41.08 \pm 10.02$ years and mean weight was $64.60 \pm 6.49 \mathrm{Kg}$. The mean body mass index (BMI) of the patients was $22.58 \pm 2.52 \mathrm{~kg} / \mathrm{m}^{2}$. [Table-1]
The numbers of patients studied in the age group 41-50 years were more as compared to other age groups. Male patients $(64.0 \%)$ were found to be more in comparison to female patients $(36.00 \%)$. [Table 2]

\section{Modified Mallampati Grading}

The maximum number of studied patients was of Class II (40\%) of Modified Mallampati Grading, while minimum patients were in class IV $(10.5 \%)$. [Table 3]

\section{Thyromental Distance}

The Thyromental Distance of studied patients was more than $6.5 \mathrm{~cm}$ in maximum number of patients $(85.0 \%)$ while minimum number of patients $(4.0 \%)$ showed Thyromental distance of less than $6.0 \mathrm{~cm}$. [Table 4]

Protrusion of jaw

The Maximum number of patients showed class I (53.5\%) protrusion of jaw while minimum number of patients showed class III (20.5\%). [Table 5]

Head Extension at Atlanto- Occipital joint (A-O joint)

The Head Extension was more than $85^{\circ}$ in maximum number of patients $(60.5 \%)$ while minimum number of patients (16\%) showed head extension between $80^{\circ}-85^{\circ}$. [Table-6]

Neck flexion at lower cervical joint

The neck flexion was more than $25^{\circ}$ in maximum number of patients $(84.5 \%)$ while minimum number of patients $(15.5 \%)$ showed neck flexion $<25^{\circ}$. [Table 7]

Maxillo-pharyngeal angle

The Maxillo-pharyngeal angle of studied patients was more than $110^{\circ}$ in maximum number of patients $(46.5 \%)$ while minimum number of patients (3.0\%) showed Maxillopharyngeal angle of less than $85^{\circ}$. [Table 8]

\section{Cormack and Lehane Grading}

Cormack and Lehane Grading of studied patients was Class I in maximum number of patients $(46.0 \%)$ while minimum number of patients showed class IV (5.5\%). [Table 9]

Correlation between different parameters of airway assessment

Table 1: Distribution of Demographic data of studied population.

\begin{tabular}{|l|l|l|l|}
\hline S No & Demographic data & Mean \pm SD & Range \\
\hline 1 & Age $($ Year $)$ & $41.08 \pm 10.2$ & $18-58$ \\
\hline 2 & Weight $(\mathrm{kg})$ & $64.60 \pm 6.49$ & $51-75$ \\
\hline 3 & Height $(\mathrm{cm})$ & $162 \pm 0.60$ & $148-178$ \\
\hline 4 & BMI $(\mathrm{kg} / \mathrm{m} 2)$ & $22.58 \pm 2.52$ & $18.07-24.36$ \\
\hline
\end{tabular}

Data is presented in mean \pm SD and absolute numbers. BMI- Body Mass Index

Table 2: Distribution of patients based on age and gender $(\mathbf{n}=\mathbf{2 0 0})$

\begin{tabular}{|l|l|l|l|l|}
\hline $\begin{array}{l}\text { S } \\
\text { No }\end{array}$ & $\begin{array}{l}\text { Age Group } \\
\text { (Years) }\end{array}$ & Male & Female & Total \\
\hline 1 & $\leq 30$ & $22(11.00 \%)$ & $19(9.50 \%)$ & $41(20.50 \%)$ \\
\hline 2 & $31-40$ & $34(17.00 \%)$ & $12(6.00 \%)$ & $46(23.00 \%)$ \\
\hline 3 & $41-50$ & $49(24.50 \%)$ & $20(10.00 \%)$ & $69(34.50 \%)$ \\
\hline 4 & $51-60$ & $23(11.50 \%)$ & $21(10.50 \%)$ & $44(22.00 \%)$ \\
\hline 5 & Total & $128(64.0 \%)$ & $72(36.00 \%)$ & $200(100.0 \%)$ \\
\hline
\end{tabular}

Data is presented as absolute numbers and in percentage

Table 3: Showing Modified Mallampati Grading of studied patients $(\mathbf{n}=\mathbf{2 0 0})$

\begin{tabular}{|l|l|l|l|}
\hline S No & Mallampati Test & Frequency $(\mathbf{n = 2 0 0})$ & Percentage \\
\hline 1 & Grade I & 49 & 24.5 \\
\hline 2 & Grade II & 80 & 40.0 \\
\hline 3 & Grade III & 50 & 25.0 \\
\hline 4 & Grade IV & 21 & 10.5 \\
\hline
\end{tabular}




\section{Anwar et al: Prediction of Difficult Airway}

The Modified Mallampati grading, Cormack and Lehane grading, Maxillo-pharyngeal (M-P) angle, Atlanto-occipital (A-O) joint extension and Thyromental (T-M) distance were correlated together. [Table 10]

Maximum number of patients was in class I of Cormack and Lehane grading (46.0\%), maxillo-pharyngeal (M-P) angle $(46.5 \%)$, atlanto-occipital (A-O) joint extension $(60.5 \%)$ and thyromental distance (TMD) $(85.0 \%)$ while Modified Mallampati classification shows maximum number of patients in class II $(40.0 \%)$. Minimum number of patients were in lowest grade in all groups. [Table 11]

Correlation between the results of different predictive test in association with easy or difficult intubation

Mallampati grading predicted easy airway in total 129 patients in which 17 patients were found to be difficult during direct laryngoscopy (Cormack and Lehane grading), and when it predicted difficult airway in 71 patients, only 11 patients were found to be difficult for direct laryngoscopy. The maxillo- pharyngeal angle test predicted easy airway in total 171 patients in which only 4 patients showed difficult airway by Cormack and Lehane grading. It predicted difficult airway in 29 patients, out of which 24 patients were found to be difficult. [Table 12]

Modified Mallampati test (MMT) sensitivity and specificity was established as $39.29 \%$ and $65.12 \%$ respectively with accuracy of $61.5 \%$. The sensitivity and specificity of Maxillo-Pharyngeal Angle was 85.71 \% and 97.09\% respectively with accuracy of $95.50 \%$. Only, Mallampati grading showed significant differences for difficult airway among all airway assessment criterions. [Table 13]

Table 4: Showing Thyromental Distance grading of studied patients $(\mathbf{n}=\mathbf{2 0 0})$

\begin{tabular}{|l|l|l|l|}
\hline $\begin{array}{l}\text { S } \\
\text { No }\end{array}$ & Thyromental Distance & $\begin{array}{l}\text { Frequency } \\
(\mathbf{n = 2 0 0})\end{array}$ & Percentage \\
\hline 1 & $>6.5 \mathrm{~cm}$ & 170 & 85.0 \\
\hline 2 & $6-6.5 \mathrm{~cm}$ & 22 & 11.0 \\
\hline 3 & $<6 \mathrm{~cm}$ & 8 & 4.0 \\
\hline & Mean \pm SD & $6.78 \pm 0.38$ & $4.9-7.4$ Range \\
\hline
\end{tabular}

Data is presented as mean $\pm \mathrm{SD}$, absolute numbers and in percentage.

The receiver operating characteristic (ROC) curve is a graphic representation of the relationship between sensitivity and specificity and is created by plotting the true positive rate against the false- positive rate at various threshold settings. In the present study, the area under ROC curve was 0.522 for Mallampati test and 0.914 with Maxillo-pharyngeal angle as predictive curve, which revealed that Maxillopharyngeal angle is more sensitive and specific for prediction of difficult airway. [Table $14 \&$ Figure 3]

Table 5: Showing Protrusion of jaw grading of studied patients $(\mathbf{n}=\mathbf{2 0 0})$

\begin{tabular}{|l|l|l|l|}
\hline S No & Protrusion of jaw & $\begin{array}{l}\text { Frequency } \\
(\mathbf{n = 2 0 0})\end{array}$ & Percentage \\
\hline 1 & Class I & 107 & 53.5 \\
\hline 2 & Class II & 52 & 26.0 \\
\hline 3 & Class III & 41 & 20.5 \\
\hline
\end{tabular}

Data is presented as absolute numbers and in percentage.

Table 6: Showing Head Extension grading of studied patients
$(\mathbf{n = 2 0 0 )}$
\begin{tabular}{|l|l|l|l|}
\hline S No & Head extension & Frequency $(\mathbf{n = 2 0 0})$ & Percentage \\
\hline 1 & $>850$ & 121 & $60.5 \%$ \\
\hline 2 & $80^{\circ}-85^{\circ}$ & 32 & $16 \%$ \\
\hline 3 & $<80^{\circ}$ & 47 & $23.5 \%$ \\
\hline
\end{tabular}

Data is presented as whole number and percentage.

Table 7: Showing Neck flexion grading of studied patients $(\mathbf{n}=\mathbf{2 0 0})$

\begin{tabular}{|l|l|l|l|}
\hline S No & Neck flexion & Frequency $(\mathbf{n = 2 0 0})$ & Percentage \\
\hline 1 & $>25^{0}$ & 169 & 84.5 \\
\hline 2 & $<25^{0}$ & 31 & 15.5 \\
\hline
\end{tabular}

Data is presented as absolute numbers and in percentage.

Table 8: Showing Maxillo-pharyngeal (MP) angle of studied patients

\begin{tabular}{|l|l|l|l|}
\hline S No & $\begin{array}{l}\text { Maxillo } \\
\text { pharyngeal angle }\end{array}$ & $\begin{array}{l}\text { Frequency } \\
(\mathbf{n = 2 0 0 )}\end{array}$ & Percentage \\
\hline 1 & $>110^{0}$ & 93 & 46.5 \\
\hline 2 & $<110-90^{0}$ & 78 & 39.0 \\
\hline 3 & $<90^{0}$ & 23 & 11.5 \\
\hline 4 & $<85^{0}$ & 6 & 3.0 \\
\hline
\end{tabular}

Data is presented as absolute numbers and in percentage.

Table 9: Showing Cormack and Lehane grading of studied patients $(\mathbf{n}=\mathbf{2 0 0})$

\begin{tabular}{|l|l|l|l|}
\hline S No & $\begin{array}{l}\text { Cormack and } \\
\text { Lehane Grading }\end{array}$ & $\begin{array}{l}\text { Frequency } \\
(\mathbf{n = 2 0 0})\end{array}$ & Percentage \\
\hline 1 & Grade I & 92 & 46.0 \\
\hline 2 & Grade II & 75 & 37.5 \\
\hline 3 & Grade III & 22 & 11.0 \\
\hline 4 & Grade IV & 11 & 5.5 \\
\hline
\end{tabular}

Data is presented as absolute numbers and percentage.

Table 10: Showing Correlation between different parameters of airway assessment

\begin{tabular}{|l|l|l|l|l|}
\hline $\begin{array}{l}\text { Modified Mallampati } \\
\text { Classification }\end{array}$ & Cormack and Lehane Grading & M-P Angle & A-O extension & T-M distance \\
\hline $\begin{array}{l}\text { I (soft palate, fauces, uvula and pillars } \\
\text { seen) }\end{array}$ & $\begin{array}{l}\text { I (Visualization of the entire laryngeal } \\
\text { aperture) }\end{array}$ & $>110^{0}$ & $>85^{0}$ & $>6.5 \mathrm{~cm}$ \\
\cline { 1 - 3 } II (soft palate, fauces, and uvula seen ) & $\begin{array}{l}\text { II (Visualization of parts of the laryngeal } \\
\text { aperture or the arytenoids) }\end{array}$ & $<110-90^{0}$ & $80-85^{0}$ & $6-6.5 \mathrm{~cm}$ \\
\cline { 1 - 3 } III (soft palate and base of uvula seen) & $\begin{array}{l}\text { III (No part of the glottis can be seen except } \\
\text { the epiglottis) }\end{array}$ & $<90^{0}$ & $<6 \mathrm{~cm}$ \\
\hline IV(soft palate not visible) & IV (Not even the epiglottis can be seen) & $<85^{0}$ & $<80^{0}$ & \\
\hline
\end{tabular}

Table 11: Distribution of studied patients in different parameters $(n=200)$

\begin{tabular}{|c|c|c|c|c|c|}
\hline Grade & Mallampati Classification & Cormack and Lehane & M-P angle & A-O Extension & T-M distance \\
\hline I & $49(24.5 \%)$ & $92(46.0 \%)$ & $93(46.5 \%)$ & $121(60.5 \%)$ & $170(85.0 \%)$ \\
\hline II & $80(40.0 \%)$ & $75(37.5 \%)$ & $78(39.0 \%)$ & \multirow[t]{2}{*}{$32(16.0 \%)$} & \multirow[t]{2}{*}{$22(11.0 \%)$} \\
\hline III & $50(25.0 \%)$ & $22(11.0 \%)$ & $23(11.5 \%)$ & & \\
\hline IV & $21(10.5 \%)$ & $11(5.5 \%)$ & $6(3.0 \%)$ & $47(23.5 \%)$ & $8(4.0 \%)$ \\
\hline
\end{tabular}

Data is presented as absolute numbers and percentage. 
Anwar et al: Prediction of Difficult Airuay

Table 12: Correlation between the result of different predictive test in association with easy or difficult intubation $(\mathrm{n}=\mathbf{2 0 0})$

\begin{tabular}{|c|c|c|c|c|c|}
\hline & \multirow[t]{2}{*}{ Assessment } & \multirow[t]{2}{*}{ Number of patients } & \multicolumn{2}{|c|}{ Final Diagnosis } & \multirow[t]{2}{*}{ Kappa value } \\
\hline & & & Easy & Difficult & \\
\hline \multirow[t]{2}{*}{ Mallampati classification } & Grade I, II (Easy) & 129 & 112 & 17 & \multirow[t]{2}{*}{0.027} \\
\hline & Grade III, IV(difficult) & 71 & 60 & 11 & \\
\hline \multirow[t]{2}{*}{ Cormack and Lehane } & Grade I, II (Easy) & 167 & 167 & 0 & \multirow[t]{2}{*}{0.903} \\
\hline & Grade III, IV (difficult) & 33 & 5 & 28 & \\
\hline \multirow{2}{*}{$\begin{array}{l}\text { Maxillo pharyngeal Angle } \\
\text { (MP-A) test }\end{array}$} & (Easy) & 171 & 167 & 4 & \multirow[t]{2}{*}{0.816} \\
\hline & Difficult & 29 & 5 & 24 & \\
\hline \multirow[t]{2}{*}{ A-O extension } & Easy $\geq 85-80^{\circ}$ & 153 & 142 & 11 & \multirow[t]{2}{*}{0.337} \\
\hline & Difficult $\leq 80^{\circ}$ & 47 & 30 & 17 & \\
\hline \multirow[t]{2}{*}{ T-M distance } & Easy & 180 & 170 & 10 & \multirow[t]{2}{*}{0.717} \\
\hline & Difficult & 20 & 2 & 18 & \\
\hline
\end{tabular}

Data is presented as absolute numbers, percentage and kappa value

Table 13: Showing Sensitivity and specificity with PPV and NPV of different test

\begin{tabular}{|l|l|l|l|l|l|}
\hline Different Tests & Sensitivity & Specificity & $\begin{array}{l}\text { Positive } \\
\text { Predictive value }\end{array}$ & $\begin{array}{l}\text { Negative Predictive } \\
\text { Value }\end{array}$ & $\begin{array}{l}\text { Accuracy } \\
\text { Modified Mallampati test }\end{array}$ \\
\hline A-O extension & $39.29 \%$ & $65.12 \%$ & $15.49 \%$ & $86.82 \%$ \\
\hline T-M distance & $60.71 \%$ & $82.56 \%$ & $36.17 \%$ & $92.81 \%$ \\
\hline Maxillo-pharyngeal Angle (MP-A) & $64.29 \%$ & $98.84 \%$ & $90.00 \%$ & $91.50 \%$ \\
\hline Cormack and Lehane test & $85.71 \%$ & $97.09 \%$ & $82.76 \%$ & $94.44 \%$ \\
\hline
\end{tabular}

Data is presented as percentage.

Table 14: Showing Receiver Operating Characteristic Curve (ROCC) for Mallampati Score and Maxillo-pharyngeal Angle as Predictive Test

\begin{tabular}{|l|l|l|l|}
\hline \multirow{2}{*}{$\begin{array}{l}\text { Test Result } \\
\text { Variable(s) }\end{array}$} & $\begin{array}{l}\text { Area Under } \\
\text { the Curve }\end{array}$ & $\begin{array}{l}\text { Asymptotic 95\% Confidence } \\
\text { Interval }\end{array}$ \\
\cline { 3 - 4 } & & $\begin{array}{l}\text { Lower } \\
\text { Bound }\end{array}$ & $\begin{array}{l}\text { Upper } \\
\text { Bound }\end{array}$ \\
\hline Mallampati test & 0.522 & 0.406 & 0.638 \\
\hline $\begin{array}{l}\text { Maxillo-pharyngeal } \\
\text { angle }\end{array}$ & 0.914 & 0.837 & 0.992 \\
\hline
\end{tabular}

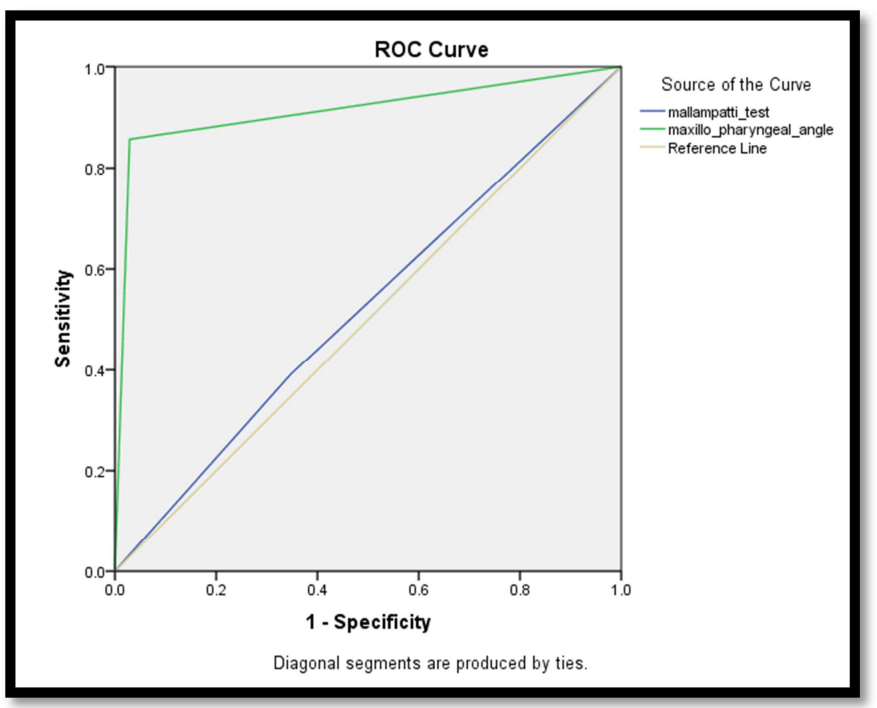

Figure 3: Receiver Operating Characteristic Curve (ROCC)

\section{Discussion}

Difficult airway is resultant of incomplete structural arrangements during direct laryngoscopy and may occur due to the combination of numerous minor physical anomalies when no single factor is rigorously unusual. Unanticipated difficult airway to maintain ventilation is one of the main contributing factors for significant morbidity and mortality in patients under general anesthesia. A number of studies have attempted to combine physical factors to predict difficult laryngoscopy but none could succeed.

Preoperative airway assessment is based on the examination of one or several known predictors of difficult airway management but the existing predictors are not sensitive or specific enough for routine use. Difficult airway is a multifactorial problem and no single test can foresee difficulty precisely. ${ }^{[4]}$

The American Society of Anaesthesiologists (ASA) recommends a pre-operative airway assessment, based on anatomical variable but without any elaboration. ${ }^{[9]}$ Consequently it is left to the discretion of the anaesthesiologist himself. In certain patients, the causes are obvious such as the facial deformity, limited movement of the tempromandibular joint, hypo-pharyngeal disease, limited head extension, reduced distance between mandible and hyoid bone and sterno-mental distance.

The present study presents a novel estimate of diagnostic accuracy for subjective prediction of difficult airway by associations of various physical and radiological indices to determine their prevalence. The study was conducted on 200 patients whose craniofacial indices were within normal limits. Majority of patients $(64 \%)$ were male while female were only $36 \%$. Butiyani $\mathrm{P}$ et al also studied 556 patients with age group between 18 to 65 years and they reported similar results in their study. ${ }^{[10]}$

The incidence of difficult laryngoscopy (1.5\% -13\%), difficult intubation $(1.2 \%-3.8 \%)$ and difficult mask ventilation $(0.01 \%-0.05 \%)$ are subject to variability but they do occur. In the present study, the incidence of difficult intubation was $14 \%$ while study of Shiga et al, ${ }^{[11]}$ reported difficult laryngoscopy in $5.8 \%$ of patients. The incidence of difficult intubation in the study of Khan et al was $5.7 \%$ where as in trial study of Leopald, it was $12 \%$. The difference in incidence may be due to smaller size sample of present study. ${ }^{[12]}$

Mallampati et al emphasized the importance of the base of 
the tongue in determining the difficulty of laryngoscopy which is a simple, reproducible, and reliable but has limited discriminative power for difficult airway. ${ }^{[13]}$ Upper bite test could also reliably predict difficult intubation and is associated with the least inter observer variability, which adds to its advantage as an airway assessment test. ${ }^{[14]}$ Lewis et al conducted a study to determine which method of testing could effectively predict the difficult airway. ${ }^{[15]}$

Arne et $\mathrm{al},{ }^{[16]}$ did not consistently ensure accurate evaluation of difficult laryngoscopy even by calculating airway indices that incorporate many assessment criteria, those proposed by Wilson et al, ${ }^{[17]}$ with sensitivity of $75 \%$, specificity of $88 \%$, with positive predictive value of $9 \%$ and negative predictive value of $99 \%$

Mallampati grading was combined with factors such as obesity, short neck, abnormal teeth, receding mandible, facial edema, and swollen tongue in the obstetric population. White and Kander reported that an increase in the anterior and posterior depth of mandible, a decrease in atlanto-occipital gap and CI-C2 gap and limitation of movement at the tempromandibular joint were the factors that determined whether direct laryngoscopy would be easy or difficult. ${ }^{[18]}$

Lundstrom LH et al, ${ }^{[19]}$ and Shiga et al demonstrated that the Modified Mallampati Test was inadequate for prediction of difficult airway when used alone. Another study also reported that MMT has limited accuracy for predicting difficult airway and thus is may not be a useful screening test. In the present study, Mallampati grading showed significant differences for prediction of difficult airway among all airway assessment criterions.

In contrast, the Maxillo- pharyngeal angle (MP-A) technique appears to be promising as a good diagnostic performance as it is closely related with the extension of the neck at the atlanto- occipital joint where restriction of neck extension is associated with difficult laryngoscopy. ${ }^{[8]}$

Modified Mallampati test (MMT) sensitivity and specificity was found as $39.29 \%$ and $65.12 \%$ respectively with accuracy was of $1.5 \%$. The sensitivity and specificity of MaxilloPharyngeal Angle was $85.71 \%$ and $97.09 \%$ respectively with accuracy of $95.50 \%$. These results were parallel to previously conducted studies. Its area under cover of ROC curve, covered nearly $83 \%$ of the graph. In addition, positive likelihood ratio (LR+) was 6.53, making it a diagnostically accurate test. The Maxillo- pharyngeal angle test has 26 times the odds of correct prediction as compared to false prediction and showed $95.50 \%$ accuracy.

The higher positive predictive value (PPV) of MaxilloPharyngeal angle signifies that the positive test of this technique i.e. when M P angle is less than $90^{\circ}$, is more accurate for prediction of difficult airway as compared to Modified Mallampati grade scoring(Class III and IV).

It has been shown by several investigators that the Mallampati score is not sensitive enough for clinical practice. The inaccurate prediction of difficult laryngoscopy by Modified Mallampati grade may be due to its poor to moderate inter-assessor reliability, due to absence of a definite demarcation between classes and it does not assess neck mobility. It was suggested that MMT is better at predicting difficult laryngoscopy associated with soft tissue changes thus benefited obstetric and obese population, but these patients were not included in the present study hence better accuracy of MMT could not be found in the present study.

Further, thyromental distance $\leq 7 \mathrm{~cm}$, or sternomental distance $\leq 12.5 \mathrm{~cm}$ had low sensitivity and specificity. Due to the quantitative nature of sternomental distance (SMD), thyromental distance (TMD), and inter- incisor gap (IIG), it is challenging to differentiate the class easily and precisely.

Nevertheless, the maxillo-pharyngeal angle is measured electronically on lateral cervical radiograph with head in the neutral position. The obtained value of M-P angle is accurate and not influenced by inter-assessor variability and can be easily retrieved for re-examination. These data may be obtained at the bed side to augment the preoperative assessment.

Similarly, higher negative predictive value (NPV) indicates a negative MP-A test rule out difficult laryngoscopy more readily than a negative Modified Mallampati grade score. The original study done by Gupta et al assessed the correlation between various airway assessment parameters and concluded that visualization of the larynx upon direct laryngoscopy was impossible when the MP-A was less than $90^{\circ}{ }^{[20]}$ The present study is in correlation with their study.

The receiver operating characteristic curve (ROCC) is a graphic representation of the relationship between sensitivity and specificity. An important advantage of ROCC analysis over traditional sensitivity and specificity analysis is that the area under the ROC curve is independent both of the cutpoint criteria chosen and the prevalence of outcome of interest. A model is considered perfect when the ROC area is 1.0 , useless when it is $<0.5$ (that is under a line of no discrimination). Showed low accuracy if between 0.5 and 0.7 , and becomes useful with an area 0.7 .

In the present study, the area under ROC curve was 0.522 for Mallampati test and 0.914 with Maxillo-pharyngeal angle as predictive curve, which showed that Maxillo-pharyngeal angle is more sensitive and specific for prediction of difficult airway.

Naguib et al demonstrated that methods of evaluation that involved combining different clinical (or clinical and radiological) criteria appeared to be sensitive in predicting difficult intubation. The ROC areas observed in their study were high ( 0.933 and 0.973 , respectively) indicating good discrimination with the models. ${ }^{[21]}$

Samra et al reported that soft tissue radiographs (measured from MRI scans) did not identify any measurable parameters that could categorically define the difference between unexpectedly difficult-to-intubate patients and control subjects. ${ }^{[22,23]}$

The variable results in all these studies was due to difficult intubation being uncommon and none of the predictors could yield a high positive predictive value for difficult airway. There may be ample room for improvement, based on a rigorous, evidence based and systematic approach.

\section{Limitations}

- The structural analysis of the present study was two dimensional and did not include the whole upper airway structures, indicating a methodological drawback for investigation. 
- Details on the number of attempts at intubation, time taken for intubation and physiological derangements were not recorded in this study.

- In reality, it was difficult to obtain numerous control patients from the general adult population.

\section{Conclusion}

The combination of various physical indices and measurement of maxillo- pharyngeal angle on lateral cervical radiograph in parallel is more sensitive and specific with clinically relevant higher discriminative power and no single airway test has provided a high index of sensitivity and specificity for prediction of difficult airway. The present study adds to the numerous other studies dealing with the prediction of difficult laryngoscopy.

\section{References}

1. AK Norskov. Diagnostic accuracy of anaesthesiologist's prediction of difficult airway management in daily clinical practice; a cohort study of 188064 patients registered in the Danish anaesthesia database. Anaesthesia 2015; 70: 272-81.

2. Gupta S, Sharma R, Jain D. Airway assessment: predictors of difficult airway. Indian J. Anaesth 2005; 49:257-62.

3. Ramachandran K, Bhishma R. Unexpected difficult airway. Anaesthesia2003; 58: 392-3

4. Wanderley GH, Lima LC, Couceiro TC, Silva WV, Coelho RQ, Lucena AC, Soares AD. Clinical Criteria for Airway Assessment: Correlations with Laryngoscopy and Endotracheal Intubation Conditions. Open Journal of Anesthesiology 2013; 3: 320-5.

5. Cormack RS, Lehane J. Difficult tracheal intubation in obstetrics. Anaesthesia 1984; 39: 1105-11.

6. Kamalipour H, Bagheri M, Kamlai K. Lateral neck radiographs for prediction of difficult oro-tracheal intubation. Eur J Anaesthesiol 2005; 22: 687-93.

7. Liu GY, Shen YY, Yan YH, Yao MH, Xue JX. Lateral neck radiography in prediction of difficult laryngoscopy in Chinese patients. Int J Clin Exp Med 2016; 9:2184-92.

8. Hassan MH, Fung EM, Zaini RH, Hassan SK, Seevaunnamtum P, Mazlan MZ, Mohamad NA. A Comparison between Measured Maxillo-pharyngeal Angle on Lateral Cervical Radiograph with Modified Mallampati Classification in Predicting Difficult Laryngoscopy: A Blinded Interventional Study. Malaysian Journal of Medicine and Health Sciences 2018; 14: 51-6.

9. A Report by the American Society of Anesthesiologists Task Force on
Management of the Difficult Airway. Practice guidelines for management of the difficult airway. Anesthesiology 1993; 78 :597602 .

10. Butiyani P, Unjhawala T, Sale HK, Chandrashekar S, Dangat G, Prakash L. Comparison of Upper Lip Bite Test, Ratio of Height to Thyromental Distance, and Maxillo-pharyngeal Angle to Predict Difficult Laryngoscopy. Int J Sci Stud 2018; 5:1-6.

11. Shiga T, Wajima Z, Inoue $T$, Sakamoto A. Predicting difficult intubation in apparently normal patients-a meta-analysis of bedside screening test performance. The Journal of the American Society of Anesthesiologists 2005; 103: 429-37.

12. Khan ZH. A Comparison of the Upper Lip Bite Test (a Simple New Technique) with Modified Mallampati Classification in Predicting Difficulty in Endotracheal Intubation: A Prospective Blinded Study. Anesth Analg 2003; 96: 595-9.

13. Mallampati SR, Gatt SP, Gugino LD, Desai SP, Waraksa B, Freiberger D, Liu PL: A clinical sign to predict difficult tracheal intubation: A prospective study. Can J Anaesth1985; 32: 424-34.

14. Khan ZH, Mohammadi M, Rasouli MR. The diagnostic value of the upper lip bite test combined with sternomental distance for prediction of easy laryngoscopy and intubation: A prospective study. Anesth Analg 2009; 109: 822-4.

15. Lewis M, Keramati S, Benumof JL. What is the best way to determine oropharyngeal classification and mandibular space length to predict difficult laryngoscopy? Anesthesiology 1994; 81:69-75.

16. Arne J, Descoins P, Fusciurdi J, Ingrand P, Ferrier B, Boudigues D, et al.Preoperative assessment for difficult intubation in general and ENT surgery: predictive value of a clinical multivariate risk index. Br J Anaesth 1998; 80: 140-6.

17. Wilson ME, Spiegelhalter D, Rohertson JA, Lesser P. Predicting difficult intubation. Br J Anaesth 1988; 61:211-6.

18. White A, Kander PL. Anatomic factors in difficult direct laryngoscopy. Br J Anaesth 1975; 47:468-74.

19. Lundstrøm LH, Andersen MV, Møller AM, Charuluxananan S, L'hermite J,Wetterslev J. Poor prognostic value of the Modified Mallampati Score, A Meta-Analysis Involving 177088 Patients.Br J Anaesth 2011:107(5);659-67.

20. Gupta K, Gupta PK. Assessment of difficult laryngoscopy by electronically measured maxillo-pharyngeal angle on lateral cervical radiograph: A prospective study. Saudi J Anaesth 2010; 4:158-62.

21. Naguib M, Malabarey T, Satli RA, Damegh SA, Samarkandi AH. Predictive models for difficult laryngoscopy and intubation. A clinical, radiological and three dimensional computer imaging study. Can J Anesth 1999; 46:748-59.

22. Samra SK, Schork MA, Guinto FC. A study of radiologic imaging techniques and airway grading to predict difficult endotracheal intubation. J Clin Anesth 1995; 7: 373-9.

23. Adnet F, Borron SW, Dumas JL, Lapostolle F, Cupa M, Lapandry C. Study of the 'sniffing position' by magnetic resonance imaging. Anaesthesiology 2001; 94: 83-6.

Copyright: (C) the author(s), publisher. Academia Anesthesiologica International is an Official Publication of "Society for Health Care \& Research Development". It is an open-access article distributed under the terms of the Creative Commons Attribution Non-Commercial License, which permits unrestricted non-commercial use, distribution, and reproduction in any medium, provided the original work is properly cited.

How to cite this article: Anwar U, Gupta K, Gupta PK, Singh I, Kumar A, Kalra P. Prediction of Difficult Airway by Correlating Physical Indices with Maxillo-Pharyngeal Angle, Measured on Lateral Cervical Radiograph-an Analytical Study. Acad. Anesthesiol. Int. 2018;3(1):1218.

DOI: dx.doi.org/10.21276/aan.2018.3.1.4

Source of Support: Nil, Conflict of Interest: None declared. 